\title{
Intraspecific competition controls spatial distribution and social organisation of the coral-dwelling goby Gobiodon histrio
}

\author{
J.-P. A. Hobbs*, P. L. Munday \\ School of Marine Biology and Aquaculture and Centre for Coral Reef Biodiversity, James Cook University, Townsville, \\ Queensland 4811, Australia
}

\begin{abstract}
The role of competition in regulating reef fish populations has been controversial. Here, we test the effect of intraspecific competition on the spatial distribution and social organisation of Gobiodon histrio, an obligate coral-dwelling goby that inhabits the branching coral Acropora nasuta. At Lizard Island (Great Barrier Reef), social groups of G. histrio consisted of either a single individual or a breeding pair and occupied $98 \%$ of $A$. nasuta colonies, indicating that corals are a limiting resource. Furthermore, there was a positive relationship between fish size and coral size, with small, single G. histrio mostly occupying small corals ( $<15$ to $20 \mathrm{~cm}$ diameter) and larger paired fish occupying large corals (>15 to $20 \mathrm{~cm}$ diameter). A manipulative experiment involving small and large corals demonstrated that this positive relationship between fish size and habitat size was due to sizebased competition for large corals. Small and large G. histrio exhibited a similar preference for large corals (using large corals in approximately $80 \%$ of trials), but small fish were usually excluded from large corals in the presence of a larger fish. Small fish were more likely to use large corals in the presence of a single adult (38\% of trials) than in the presence of an adult pair ( $8 \%$ of trials), suggesting that small fish may be able to enter a large coral following the loss of one individual in a breeding pair. The presence of a threshold coral size for the formation of breeding pairs means that an individual's ability to compete for large corals will influence its reproductive success.
\end{abstract}

KEY WORDS: Intraspecific competition · Coral-reef fish · Habitat limitation · Dominance hierarchy · Gobiodon · Gobiidae · Acropora

\section{INTRODUCTION}

Determining the mechanisms that regulate a species' distribution and abundance is of fundamental importance to ecologists. Competition for space was originally assumed to be the principal process controlling the distribution and abundance of reef fishes (Smith \& Tyler 1972). However, when well-designed field experiments did not detect significant effects of competition on the densities of reef fishes (Doherty 1982, 1983, Jones 1987), the focus of attention shifted to whether recruitment was generally insufficient for populations to reach their carrying capacity (Doherty \& Williams 1988, Doherty 1991). Following a resurgence of interest in studying competition, it is now clear that, in at least some reef fishes, inter- and intraspecific competition can influence patterns of abundance (Buchheim \& Hixon 1992, Robertson 1996, Munday et al. 2001, Munday 2004), distribution (Clarke 1992, Robertson 1996, Munday et al. 2001), habitat use (Robertson \& Gaines 1986, Robertson 1996, Munday et al. 2001), feeding behaviour (Coates 1980, Clark 1992, Webster \& Hixon 2000), growth (Doherty 1982，1983, Jones 1987, 1991, Munday 2001), maturation (Jones 1987, Booth 1995) and mortality (Schmitt \& Holbrook 1999, Holbrook \& Schmitt 2002).

Habitat is a limiting resource for some small reef fishes (Buchheim \& Hixon 1992, Clarke 1996, Robertson 1996, Schmitt \& Holbrook 2000, Munday et al. 2001, 2002) and consequently, intraspecific competi- 
tion may determine the distribution of individuals among habitat patches. The outcome of intraspecific competitive interactions among fishes is typically sized-based, with larger individuals usually securing the best habitat patches (Itzkowitz et al. 1998, Webster \& Hixon 2000, Holbrook \& Schmitt 2002). Larger habitat patches are often preferred because they can support larger social groups and are valuable breeding sites. For example, in some anemone fishes, breeding pairs occupy large anemones, which they defend against intruders (Ross 1978, Fricke 1979). Smaller conspecifics are found on small anemones or on the non-preferred, peripheral areas of larger anemones (Ross 1978, Ochi 1989). Similarly, nearly all seawhips above a critical size are occupied by a breeding pair of seawhip gobies Bryaninops yongei but juveniles are mostly found alone on much smaller seawhips (Munday et al. 2002). In the coral-dwelling goby Paragobiodon echinocephalus, breeding pairs occupied corals greater than $10 \mathrm{~cm}$ average diameter, while smaller corals were occupied by single fish (Kuwamura et al. 1994). These examples indicate that intraspecific competition can determine the spatial distribution of individuals among different sized habitat patches and thus, has important consequences for the social organisation of reef fish populations.

Effects of intraspecific competition on social organisation are likely to be greatest among habitat specialists because habitat space is often a limiting resource for these species (Munday \& Jones 1998). Gobiodon histrio is a habitat specialist of the branching coral Acropora nasuta (Munday et al. 1997), relying on this coral for shelter, food and a site for reproduction (Patton 1994, Nakashima et al. 1996). The abundance of G. histrio is closely correlated to the abundance of A. nasuta coral colonies (Munday et al. 1997), indicating that this habitat is a limited resource. Furthermore, $G$. histrio competes with other Gobiodon species for access to colonies of $A$. nasuta (Munday et al. 2001). However, there are rarely more than 2 G. histrio individuals per coral colony (less than $2 \%$ of social groups, J.-P. A. Hobbs unpubl. data), regardless of coral colony size, indicating that social interactions determine the maximum size of social groups (Munday et al. 1998). This interaction between competition for habitat space and strict social organisation is likely to have important consequences for the distribution of individuals among habitat patches, especially if access to habitats is determined by a size-based hierarchy.

In this study, we investigated the effects of intraspecific competition on the distribution of Gobiodon histrio among coral colonies. If habitat is a limited resource, with larger corals conferring greater advantages, and individuals compete for corals according to a size-based hierarchy, we predicted that (1) most habitat patches would be occupied, (2) there would be a positive relationship between coral colony size and the body size of fish inhabiting these corals and (3) all fish would exhibit a preference for large corals, but small fish would be excluded from large corals in the presence of a larger fish. To test these predictions, we first determined the proportion of preferred coral colonies occupied by $G$. histrio and then examined the relationship between coral colony size and the size of G. histrio inhabiting these corals. Finally, we used laboratory experiments to test if small and large fish have the same habitat preferences, and if size determines the outcome of competitive interactions for habitat patches.

\section{MATERIALS AND METHODS}

Study site and species. This study was conducted between September 2001 and October 2002 at Lizard Island $\left(14^{\circ} 40^{\prime} \mathrm{S}, 145^{\circ} 28^{\prime} \mathrm{E}\right)$ on the Great Barrier Reef, Australia. Sampling was undertaken on 6 lagoonal reefs that form part of the extensive reef complex surrounding Lizard Island. Gobiodon histrio preferentially inhabits colonies of Acropora nasuta at Lizard Island and competitively excludes other coral-dwelling gobies from colonies of this coral (Munday et al. 1997, 2001). G. histrio usually has 2 colour forms: a spotted 'erythrospilus' morph and a striped 'histrio' morph (Munday et al. 1999). Although a recent molecular analysis has revealed that each morph is a valid species (Munday et al. 2004), they are ecologically identical and competitively equivalent (Munday 2004). Therefore, for the purpose of this study they are considered together as G. histrio. Nevertheless, only individuals of the same 'morph' were tested against each other during the competition experiments.

Relationship between habitat patch size and fish size. If a size-based competitive hierarchy determines the distribution of Gobiodon histrio individuals among corals of different sizes, then we expected that most coral colonies would be occupied and we expected to find a positive correlation between coral colony size and the size of fish occupying these corals. To determine if colonies of Acropora nasuta are likely to be a limited resource for $G$. histrio, we examined the proportion of coral colonies that were occupied by G. histrio or other goby species. Corals between 0.5 and $5 \mathrm{~m}$ depth from 6 reefs in the Lizard Island lagoon were visually censused for the presence of gobies with the aid of an underwater light. To examine the relationship between fish size and coral size, we then measured in situ the length $(L)$, width $(W)$ and height $(H)$ of each coral colony to the nearest $\mathrm{cm}$ and calculated the average diameter $(A D=[L+W+H] / 3$; see Kuwamura et al. 1994). The fish inhabiting each coral were anaes- 
thetised using a clove oil solution (Munday \& Wilson 1997), carefully removed and transported back to the laboratory, where they were re-anaesthetised and their total length (TL) measured to the nearest $\mathrm{mm}$.

Habitat preference and intraspecific competition. We used a manipulative experiment in the laboratory to test whether the relationship between habitat patch size and body size observed in the natural population reflects the habitat preference of individual fish or is the result of intraspecific competition for large coral colonies. If intraspecific competition determines the size distribution of Gobiodon histrio among coral colonies, we predicted that individuals of all sizes would have the same preference towards larger corals but small individuals would be excluded from large corals in the presence of larger individuals.

The test arena consisted of circular, plastic tanks, $110 \mathrm{~cm}$ in diameter and $50 \mathrm{~cm}$ deep with a $5 \mathrm{~cm}$ layer of beach sand spread evenly over the bottom. One large colony (mean $A D=20.0 \mathrm{~cm} \pm 0.36 \mathrm{SE}$ ) and one small colony (mean $A D=11.7 \mathrm{~cm} \pm 0.22 \mathrm{SE}$ ) of Acropora nasuta were positioned on opposite sides of the tank. A. nasuta colonies were carefully removed from the reef and transported to the outdoor aquarium facility at the Lizard Island Research Station, where they were cleared of all inhabiting fish and invertebrates. Only A. nasuta colonies occupied by Gobiodon histrio were used to ensure that they were a suitable habitat for the experiment and because prior residency of other goby species could affect habitat choice (Munday et al. 2001). The position of large and small coral colonies in the tanks was determined randomly at the start of each trial. Two inflow pipes provided unfiltered seawater from opposite sides of the tank behind each of the 2 corals. In order to release fish into the aquaria, a clear plastic acclimatisation tube, $8.5 \mathrm{~cm}$ in diameter with several rows of $2 \mathrm{~mm}$ holes facilitating water flow, was placed upright in the sand in the centre of the tank, equidistant from each coral. The top of the acclimatisation tube was conical in shape and closed while the bottom remained open and buried in the sand. A string was attached to the top end of the tube and travelled along a pulley system to allow the tube to be lifted from the tank, thereby freeing the experimental fish with minimal disturbance. A standpipe, located at the front of the tank equidistant from the 2 coral positions, maintained a water depth of $350 \mathrm{~mm}$.

To determine if small- and large-bodied individuals of Gobiodon histrio had an equal preference for large coral colonies, a single small (26.2 mm TL $\pm 0.56 \mathrm{SE})$ or a single large fish $(44.1 \mathrm{~mm} \mathrm{TL} \pm 0.67 \mathrm{SE})$ was released into the experimental arena and its habitat choice monitored. Individuals between 20 and $30 \mathrm{~mm}$ (TL) were classified as small and individuals between 40 and $50 \mathrm{~mm}$ (TL) were classified as large, in accordance with the observed distribution of fish occupying small and large corals in the field. These 2 size-classes, 20 to 30 and 40 to $50 \mathrm{~mm}$ (TL), represent juveniles and adults, respectively (Hobbs et al. in press). Suitably sized fish were collected from Acropora nasuta corals in the field using clove oil anaesthetic. Collected fish were placed individually into plastic snap-lock bags, filled with fresh seawater, transported to the laboratory, measured (TL to nearest $0.1 \mathrm{~mm}$ ) and placed separately into visually isolated holding tanks that contained plastic tubes for refuge. Fish were held in aquaria for no more than $6 \mathrm{~h}$ before use. Fish removed from the experimental corals were not tested to avoid possible effects of prior residency on patterns of habitat choice. Fish were only tested once, with a new fish being used for each trial. At the commencement of each trial, a single fish was placed in the acclimatisation tube and released after $60 \mathrm{~min}$. Based on initial observations, $14 \mathrm{~h}$ was deemed a suitable time period for fish to have finalised their choice of habitat. Therefore, trials were commenced at approximately $17: 00 \mathrm{~h}$ and habitat choice recorded at 07:00 $\mathrm{h}$ the next day.

Having established the preference of small and large fish for small and large coral colonies, we then tested if these preferences were maintained by small fish in the presence of a larger fish. If a size-based competitive hierarchy determines the distribution of individuals among coral colonies, we expected that both small and large fish would prefer large coral colonies but small fish would be excluded from large corals in the presence of a larger individual. To test this hypothesis, we conducted a 2-part experiment in the test arena described above. First, to determine if a single, larger individual can displace a smaller individual from a preferred habitat, we released 1 small and 1 large fish simultaneously into the jointly preferred habitat (large coral). Second, because Gobiodon histrio form monogamous pairs, and thus a large and a small individual might remain together to establish a breeding pair, we also released one small fish and a known breeding pair into the jointly preferred habitat (large coral). The size range of experimental fish was the same as that described above. Fishers exact tests were used to compare the frequency with which small and large fish used small and large coral colonies in the presence and absence of a conspecific.

\section{RESULTS}

\section{Relationship between habitat patch size and fish size}

Colonies of Acropora nasuta appeared to be a limited resource, with $98.4 \%$ of all censused colonies occupied 


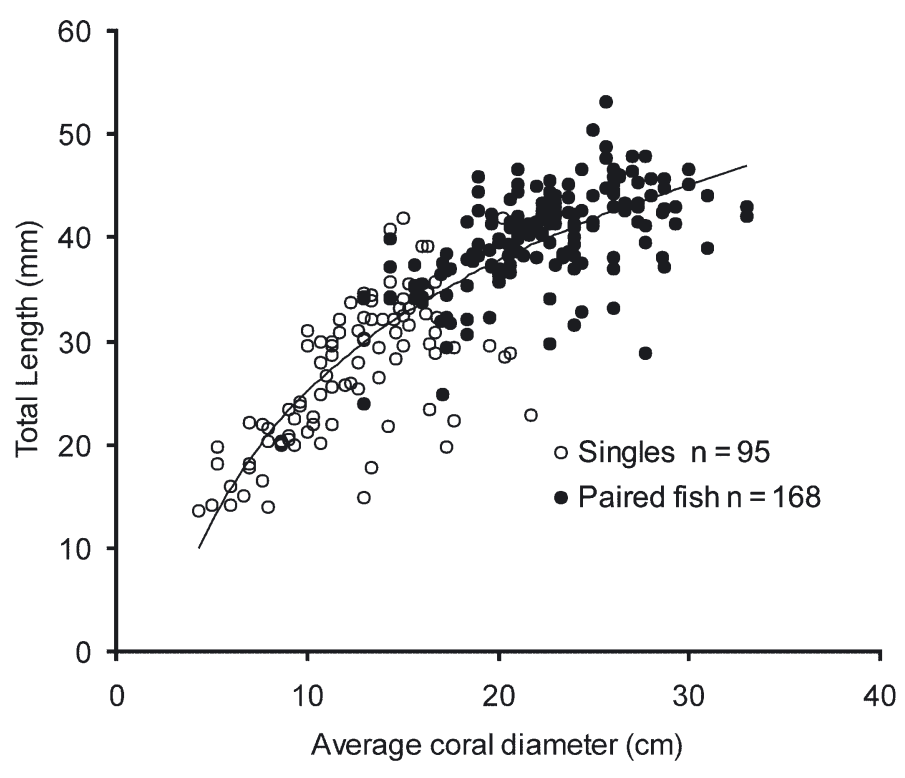

Fig. 1. Relationship between coral colony average diameter and the total length of Gobiodon histrio inhabiting each coral. $\mathrm{R}^{2}=0.72441, y=18.221 \ln (x)-16.831$

by 1 or more Gobiodon histrio ( $\mathrm{n}=182$ coral colonies). Only 3 uninhabited coral colonies were found, all less than $10 \mathrm{~cm} A D$. There was a positive, non-linear relationship between coral colony $A D$ and the size of G. histrio inhabiting each coral colony (Fig. 1$)(F=6.86$, $\mathrm{p}<0.001, \mathrm{n}=263)$. Small single fish were found in smaller coral colonies (mean $A D=12.4 \mathrm{~cm} \pm 0.40 \mathrm{SE}$ ) than larger paired fish (mean $A D=22.4 \mathrm{~cm} \pm 0.32 \mathrm{SE}$ ). Furthermore, there appeared to be a threshold coral size for the formation of breeding pairs. Corals above 15 to $20 \mathrm{~cm} A D$ were mostly occupied by a pair of G. histrio, whereas coral colonies below 15 to $20 \mathrm{~cm} \mathrm{AD}$ were mostly occupied by a single fish.

\section{Habitat preference and intraspecific competition}

Small and large Gobiodon histrio exhibited a similar preference for large coral colonies (Fishers exact test: $\mathrm{p}=1.000)$. Both small and large fish were approximately 5 times more likely to choose a large coral colony compared to a small coral colony (Fig. 2). Hence, habitat preferences explain the natural distribution of large fish in relation to coral sizes but not the presence of small fish in small coral colonies.

Small fish were usually excluded from large corals by the presence of a larger fish (Fig. 2). In the presence of a single larger conspecific, the small fish used the smaller coral in 8 of 13 trials (62\%), compared to just 5 of 30 trials $(17 \%)$ where it was released alone (Fishers exact test: $p=0.009)$. In the other 5 of 13 trials $(38 \%)$, the small and large fish occupied the larger coral together. In all 13 trials, the large fish remained in the larger coral.

The shift in habitat use by small fish was even more pronounced in the presence of an adult pair (Fig. 2). The small fish used the small coral in 11 of 12 trials $(92 \%)$, compared to 5 of 30 trials $(17 \%)$ where it was released alone (Fishers exact test: $p<0.001$ ). In the remaining trial, the smaller fish occupied the larger coral with the breeding pair (Fig. 2). In all 12 trials, both individuals of the breeding pair remained in the larger coral.

\section{DISCUSSION}

Intraspecific competition for space is likely to be prevalent among habitat specialists, affecting patterns of distribution, abundance and social organisation (Munday \& Jones 1998). Gobiodon histrio is a habitat specialist that occupies one host coral, Acropora nasuta, much more frequently than all other species of coral available on the reef (Munday et al. 1997). In this study, all colonies of $A$. nasuta large enough for pair formation ( $>15 \mathrm{~cm} A D$ ) were occupied, indicating that large corals are a limited resource. Additionally, there was a size-specific sorting of individuals among coral colonies with larger fish inhabiting larger corals and smaller fish inhabiting smaller corals. This positive relationship between habitat patch size and fish size could come about in one of 3 different ways: (1) all fish prefer large corals but a size-based dominance hierar-

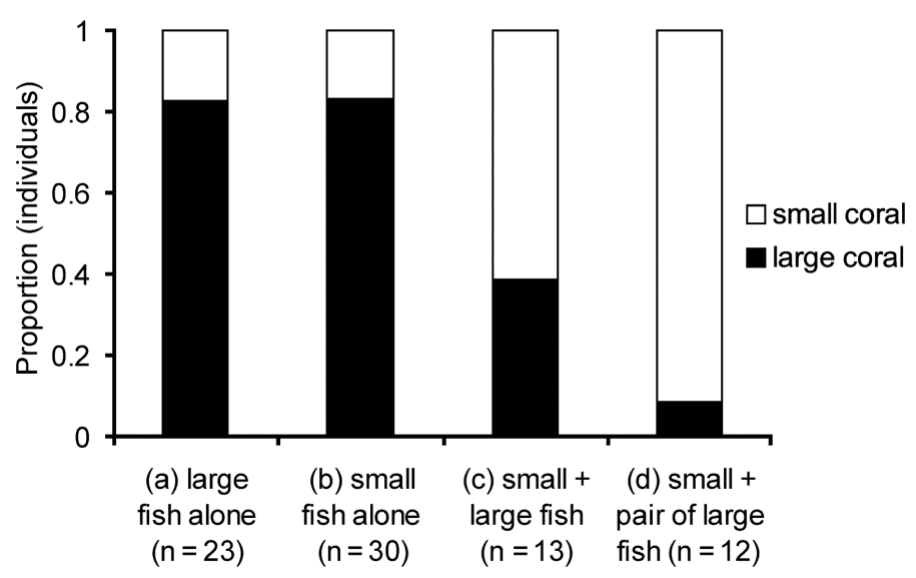

Fig. 2. Habitat use of small and large Gobiodon histrio when released into the test arena either alone or in the presence of conspecifics. Habitat use of (a) large individuals when released alone, (b) small individuals when released alone, (c) small individuals in the presence of a large conspecific and (d) small individuals in the presence of a pair of large conspecifics. ( $\mathrm{n}=$ number of trials) 
chy forces small fish to use smaller coral colonies (intraspecific competition); (2) small fish prefer small coral colonies and large fish prefer large coral colonies, and fish move to larger corals as they grow; and (3) juveniles grow faster in large coral colonies than in small corals and, thus, become larger than individuals in small corals.

The laboratory experiment demonstrated that intraspecific competition, and not size-based differences in habitat preference, was responsible for the observed distribution of Gobiodon histrio among corals. Small and large fish exhibited equal preferences for large corals, but small fish were excluded from large corals in the presence of larger fish. Differences in growth rates due to habitat size were not studied here; however, Kuwamura et al. (1996) found that there was no relationship between growth rate and coral size in a similar species, Paragobiodon echinocephalus, and therefore, the third scenario seems unlikely.

In the competition experiment, a single large fish usually excluded the smaller juvenile from the preferred habitat patch; however, there were still a considerable number of instances (38\% of trials) where the juvenile cohabited with the larger conspecific. In contrast, there was only one instance ( $8 \%$ of trials) where the juvenile cohabited with an adult pair. This indicates that juveniles are usually excluded by adult pairs, but may sometimes be able to enter a large coral when only a single adult is present, as would happen following the loss of one individual in the breeding pair. The low frequency of cohabitation of juveniles with adult pairs in the natural population $(<2 \%$ of social groups, J.-P. A. Hobbs unpubl. data) supports the notion that juveniles are excluded from coral colonies occupied by a breeding pair. Furthermore, the removal of one individual from a natural breeding pair, often results in the movement of a juvenile to reconstitute the pair (J.-P. A. Hobbs unpubl. data). This indicates that juveniles are willing to move to form a breeding pair when the opportunity exists and may often be accepted by the single remaining adult.

If juveniles move to reconstitute breeding pairs with single adults, it is interesting that juveniles were still often excluded by single adults in our laboratory experiment. The single adults used in our experiment were separated from their natural partner less than $6 \mathrm{~h}$ before use in the experiment. Therefore, there may have been insufficient time for all the single adults to develop motivation to find a new partner. Also, because the reproductive success of a breeding pair is determined by the size of both individuals in a breeding pair (Kuwamura et al. 1993), a single adult may prefer to be joined by another adult than a juvenile. Acceptance of a small juvenile as a replacement part- ner, rather than a similar sized adult, may increase with the time since separation.

Large habitat patches often confer advantages because they provide a greater abundance or better quality of resources than small habitat patches. For Gobiodon histrio, individuals probably prefer large corals because these corals are necessary for the formation of breeding pairs. In G. histrio and another coral-dwelling goby Paragobiodon echinocephalus (Kuwamura et al. 1994), there appears to be a minimum coral colony size required to support a breeding pair. Larger corals may be suitable for breeding either because they provide resources essential to reproduction (e.g. nest sites) or because only large corals provide enough food and shelter to support 2 adults. In addition, the survival rate of small $P$. echinocephalus appears to be greater in larger corals, indicating that large corals may provide better protection from predators (Kuwamura et al. 1996). Survival of individuals settling into large corals is likely to be further enhanced, compared to individuals settling into small corals, because they need not search for a coral colony of sufficient size to form a breeding pair, which is likely to involve a risk of predation. For G. histrio, larger corals are a limited resource, providing breeding sites and possible increased survivorship, which may explain the strong intraspecific competition for these larger corals.

Intraspecific competition can result from the direct exploitation of limited resources or interference behaviour among conspecifics; however, it is not always possible to clearly distinguish between these 2 mechanisms (Schoener 1983). In the case of Gobiodon histrio, all suitable-size coral colonies were occupied by a breeding pair (exploitation) and residents aggressively excluded additional conspecifics (we observed chasing and biting) from the coral colony (interference); therefore, a mix of both exploitative and interference competition was responsible for the distribution of individuals among habitat patches. A combination of these competitive mechanisms has also been observed in other site-attached fishes. For example, in social groups of planktivorous fishes, large individuals often feed upstream of small individuals, enabling them to exploit the best food resources (Coates 1980, Forrester 1991, Webster \& Hixon 2000). These same large individuals can behaviourally interfere with the feeding of subordinates, thereby further reducing the food acquisition of small individuals (Webster \& Hixon 2000).

Size-based dominance hierarchies have been observed in a number of site-attached reef fish species (Fricke \& Fricke 1977, Fricke 1979, Coates 1980, Jones 1987, Buchheim \& Hixon 1992, Webster \& Hixon 2000). In some of these species, the adults 
occupy the core area of the habitat patch and smaller subordinates inhabit the sub-optimal peripheral areas (Ross 1978, Ochi 1989, Kuwamura et al. 1993, Webster \& Hixon, 2000, Holbrook \& Schmitt 2002). In Gobiodon histrio, however, smaller fish are totally excluded from the larger preferred corals. This pattern of social organisation, where smaller individuals occupy habitats separate to the breeding pair, has also been observed in the seawhip goby Bryaninops yongei (Munday et al. 2002) and the coral-dwelling goby Paragobiodon melanosomus (Thompson 2001). The segregation of juveniles and adults clearly has the potential to influence patterns of maturation, sex allocation and reproductive success in these species. For example, social conditions experienced by juveniles have been shown to influence the timing of maturation in several reef fishes (Fricke \& Fricke 1977, Jones 1987, see review by Jones \& McCormick 2002), and segregation of juveniles and adults may affect the timing of maturation in G. histrio. Flexibility in the sex allocation patterns of adult G. histrio has been related to uncertainty in mate acquisition (Munday 2002) and it is possible that this flexibility extends to the timing of maturation. Furthermore, because all reproduction is undertaken by breeding pairs in larger corals, juveniles will need to move to larger corals to form a breeding pair. Consequently, an individual's reproductive success will depend on its ability to compete for a coral colony large enough to support a breeding pair.

In conclusion, the saturation of Acropora nasuta coral colonies supports previous reports that habitat appears limited for Gobiodon histrio, with smaller single fish inhabiting small corals and larger fish forming breeding pairs on larger corals. This positive relationship between fish size and habitat size is due to a sizebased dominance hierarchy, brought about through strong intraspecific competition for larger corals. Intraspecific competition appears to have resulted from both the limited availability of habitat and behavioural interactions that prevent the formation of large social groups. Consequently, smaller individuals are forced to inhabit corals separate to adults and this is likely to reduce their survival and potentially influence the timing of maturation. Importantly, an individual's competitive ability is likely to determine its breeding opportunities and ultimately its reproductive success.

Acknowledgements. Thanks to the staff at Lizard Island Research Station, and J. Claydon, P. Cummings, S. Hobbs and S. S. Hobbs for their valuable assistance in the field. G. R. Almany, S. Connolly, G. P. Jones, M. Pratchett and 3 anonymous reviewers provided constructive comments on earlier versions of the manuscript. This research was supported by an Australian Research Council grant to P.L.M.

\section{LITERATURE CITED}

Booth DJ (1995) Juvenile groups in a coral reef damselfish: density-dependent effects on individual fitness and population demography. Ecology 76:91-106

Buchheim JR, Hixon MA (1992) Competition for shelter in the coral reef fish Acanthemblemaria spinosa Metzelar. J Exp Mar Biol Ecol 164:45-54

Clarke RD (1992) Effects of microhabitat and metabolic rate on food intake, growth and fecundity of two competing coral reef fishes. Coral Reefs 11:199-205

Clarke RD (1996) Population shifts in two competing fish species on a degrading coral reef. Mar Ecol Prog Ser 137: 51-58

Coates D (1980) Prey-size intake in humbug damselfish, Dascyllus aruanus (Pisces, Pomacentridae) living within social groups. J Anim Ecol 49:335-340

Doherty PJ (1982) Some effects of density on the juveniles of two species of tropical, territorial damselfishes. J Exp Mar Biol Ecol 65:249-261

Doherty PJ (1983) Tropical territorial damselfishes: is density limited by aggression or recruitment? Ecology 64:176-190

Doherty PJ (1991) Spatial and temporal patterns in recruitment. In: Sale PF (ed) The ecology of fishes on coral reefs. Academic Press, San Diego, p 261-293

Doherty PJ, Williams DMcB (1988) The replenishment of coral reef fish populations. Oceanogr Mar Biol Annu Rev 26: $487-551$

Forrester GE (1991) Social rank, individual size and group composition as determinants of food consumption by the humbug damselfish, Dascyllus aruanus. Anim Behav 42: $701-711$

Fricke HW (1979) Mating system, resource defence and sex change in the Anemonefish Amphiprion akallopisos. Z Tierpsychol 50:313-326

Fricke HW, Fricke S (1977) Monogamy and sex change by aggressive dominance in a coral reef fish. Nature 266: $830-832$

Hobbs J-PA, Munday PL, Jones GP (in press) Social induction of maturation and sex determination in a coral reef fish. Proc R Soc Lond B

Holbrook SJ, Schmitt RJ (2002) Competition for shelter space causes density-dependent predation mortality in damselfishes. Ecology 83(10):2855-2868

Itzkowitz M, Vollmer G, Rios-Cardenas O (1998) Competition for breeding sites between monogamous pairs of convict cichlids (Cichlosoma nigrofasciatum): asymmetries in size and prior residence. Behaviour 135:261-267

Jones GP (1987) Competitive interactions among adults and juveniles in a coral reef fish. Ecology 68:1534-1547

Jones GP (1991) Post recruitment processes in the ecology of coral reef fish populations: a multifactorial perspective. In: Sale PF (ed) The ecology of fishes on coral reefs. Academic Press, San Diego, p 294-328

Jones GP, McCormick MI (2002) Numerical and energetic processes in the ecology of fish populations. In: Sale PF (ed) Coral reef fishes: dynamics and diversity in a complex ecosystem. Academic Press, San Diego, p 221-238

Kuwamura T, Yogo Y, Nakashima Y (1993) Size-assortive monogamy and paternal egg care in a coral goby Paragobiodon echinocephalus. Ethology 95:65-75

Kuwamura T, Yogo Y, Nakashima Y (1994) Population dynamics of the goby Paragobiodon echinocephalus and host coral Stylophora pistillata. Mar Ecol Prog Ser 103: $17-23$

Kuwamura T, Nakashima Y, Yogo Y (1996) Plasticity in size and age at maturity in a monogamous fish: effect of host 
coral and frequency dependence. Behav Ecol Sociobiol 38: 365-370

Munday PL (2001) Fitness consequences of habitat use and competition among coral-dwelling fishes. Oecologia 128: 585-593

Munday PL (2002) Bi-directional sex change: testing the growth rate advantage model. Behav Ecol Sociobiol 52: $247-254$

Munday PL (2004) Competitive coexistence among coraldwelling fishes: the lottery hypothesis revisited. Ecology 85:623-628

Munday PL, Jones GP (1998) The ecological implications of small size among coral-reef fishes. Oceanogr Mar Biol Annu Rev 36:373-411

Munday PL, Wilson SK (1997) Comparative efficacy of clove oil and other chemicals in anaesthetisation of Pomacentrus amboinensis, a coral reef fish. J Fish Biol 51:931-938

Munday PL, Jones GP, Caley MJ (1997) Habitat specialisation and the distribution and abundance of coral-dwelling gobies. Mar Ecol Prog Ser 152:227-239

Munday PL, Caley MJ, Jones GP (1998) Bi-directional sex change in a coral-dwelling goby. Behav Ecol Sociobiol 43: 371-377

Munday PL, Harold AS, Winterbottom R (1999) Guide to coral-dwelling gobies, genus Gobiodon (Gobiidae), from Papua New Guinea and the Great Barrier Reef. Rev fr Aquariol 26(1-2):53-58

Munday PL, Jones GP, Caley MJ (2001) Interspecific competition and coexistence in a guild of coral-dwelling fishes. Ecology 82:2177-2189

Munday PL, Pierce SJ, Jones GP, Larson HK (2002) Habitat use, social organization and reproductive biology of seawhip goby Bryaninops yongei. Mar Freshw Res 53:769-775

Munday PL, van Herwerden L, Dudgeon CL (2004) Evidence for sympatric speciation by host shift in the sea. Curr Biol

Editorial responsibility: Otto Kinne (Editor),

Oldendorf/Luhe, Germany
14:1498-1504

Nakashima Y, Kuwamura T, Yogo Y (1996) Both-ways sex change in monogamous coral gobies, Gobiodon spp. Environ Biol Fish 46:281-288

Ochi H (1989) Mating behaviour and sex change of the anemonefish, Amphiprion clarkii, in the temperate waters of southern Japan. Environ Biol Fish 26:257-275

Patton WK (1994) Distribution and ecology of animals associated with branching corals (Acropora spp.) from the Great Barrier Reef, Australia. Bull Mar Sci 55(1):193-211

Robertson DR (1996) Interspecific competition controls the abundance and habitat use of territorial Caribbean damselfishes. Ecology 77(3):885-899

Robertson DR, Gaines SD (1986) Interference competition structures habitat use in a local assemblage of coral reef surgeonfishes. Ecology 67:1372-1383

Ross RM (1978) Territorial behavior and ecology of the anemonefish Amphiprion melanopus on Guam. Z Tierpsychol 46:71-83

Schmitt RJ, Holbrook SJ (1999) Settlement and recruitment of three damselfishes species: larval delivery and competition for shelter space. Oecologia 118:76-86

Schmitt RJ, Holbrook SJ (2000) Habitat limited recruitment of coral reef damselfishes. Ecology 81:3479-3494

Schoener TW (1983) Field experiments on interspecific competition. Am Nat 122(2):240-285

Smith CL, Tyler JC (1972) Space resource sharing in a coral reef fish community. Bull Nat Hist Mus Los Angeles Co 14: $125-170$

Thompson VJ (2001) Habitat structure, social organisation and the reproductive biology of group-dwelling gobies. Honours thesis, James Cook University, Townsville

Webster MS, Hixon MA (2000) Mechanisms and individual consequences of intraspecific competition in a coral-reef fish. Mar Ecol Prog Ser 196:187-194

Submitted: October 1, 2003; Accepted: June 11, 2004

Proofs received from author(s): August 30, 2004 